\title{
Tracking the Ionospheric Response to the Solar Eclipse of November 03, 2013
}

\author{
Emirant Bertillas Amabayo, ${ }^{1,2}$ Simon Katrini Anguma, ${ }^{1}$ and Edward Jurua ${ }^{1}$ \\ ${ }^{1}$ Department of Physics, Mbarara University of Science and Technology, Mbarara, Uganda \\ ${ }^{2}$ Department of Physics, Busitema University, Tororo, Uganda
}

Correspondence should be addressed to Emirant Bertillas Amabayo; emirant.amabayo@gmail.com

Received 19 May 2014; Revised 28 September 2014; Accepted 8 October 2014; Published 23 October 2014

Academic Editor: Prodromos Zanis

Copyright (C) 2014 Emirant Bertillas Amabayo et al. This is an open access article distributed under the Creative Commons Attribution License, which permits unrestricted use, distribution, and reproduction in any medium, provided the original work is properly cited.

\begin{abstract}
The ionospheric dynamics is highly influenced by the solar radiation. During a solar eclipse, the moon occults the solar radiation from reaching the ionosphere, which may drastically affect the variability of the ionosphere. The variability of total electron content (TEC) observed by dual frequency Global Positioning System (GPS) receivers has made it possible to study effects of solar eclipse on the ionosphere. Total eclipse occurred on November 03, 2013, and the maximum amplitude was visible at Owiny in northern Uganda. Ionospheric behavior during this eclipse was analysed by using TEC data archived at Mbarara (MBAR), Malindi (MAL2), Eldoret (MOIU), and Kigali University (NURK) International GPS Satellite (IGS) stations. TEC variations of four consecutive days were used to study instantaneous changes of TEC during the eclipse event. The results generally show TEC decrease at the four stations. However, a maximum perturbation amplitude of $\geq 20$ TECU was observed at MAL2 (18:00-20:00 UT) which is further south of the equator than the other stations. TEC enhancement and depletion were observed during the totality of the eclipse at MOIU, MBAR, NURK, and MAL2 (13:00-15:00 UT). This study found out that the ionospheric TEC over East Africa was modified by wave-like energy and momentum transport and obscuration of the solar disc due to the total solar eclipse.
\end{abstract}

\section{Introduction}

Solar eclipse occurred on November 03, 2013, and this was observed in different parts of the world. The maximum amplitude of this total eclipse was observed at Owiny in northern Uganda. During solar eclipse, the moon passes between the sun and the earth, thereby occulting solar radiation from reaching the earth when the three celestial bodies are aligned in a syzygy. This may drastically affect the dynamics of the ionosphere. Observation of solar eclipse events has been applied in the field of ophthalmology and optometry to study the risk of solar retinopathy. Psychiatrists have investigated the impact of total solar eclipses on the incidences of suicide. In addition, sociologists investigate the impacts of media hypercoverage, greater social cohesion, tourism, and public disruptions related to the eclipse events. Scientists have investigated the response of the earth's environment to the abrupt and brief disturbance of solar radiation during the eclipse events [1] (references herein). These environmental effects cover photochemistry, meteorology, gravity waves, boundary layer physics, and the ionosphere [1-4] (references herein). The ionospheric response to solar eclipse events has mainly been investigated using techniques such as rockets, incoherent radar systems, ionosondes, satellite measurements, GPS, and theoretical modeling [5] (references herein).

The ionization of gas molecules and/or atoms in the ionosphere by the ultraviolet radiation and X-rays from the sun depends on solar intensity, solar cycle, and seasons [6]. These external factors affect ionization in the ionosphere simultaneously with the internal processes such as chemical reactions amongst the gas molecules and atoms, electrodynamic drifts, and neutral wind effects among others [6]. Since solar eclipse progressively reduces the solar spectral flux, the layers of the ionosphere are equally disturbed. Furthermore, at the lower edges of the ionosphere, recombination coefficient is 
higher than the recombination rate at higher altitudes. This leads to the lowering of ionization at the lower edges of the ionosphere. Again, the loss rate of ionization at different layers of the ionosphere depends on the chemical composition of each layer [6] (references herein). Further asserted that, in the $\mathrm{F} 1$ layer, the $\mathrm{NO}^{+}$and $\mathrm{O}^{+}$ions become dominant. A decrease in electron density is observed during an eclipse event in the F1 layer. The decrease in electron density occurs without any time delay as the loss rate of $\mathrm{NO}^{+}$and $\mathrm{O}_{2}{ }^{+}$is higher in the $\mathrm{F} 1$ region. In the $\mathrm{F} 2$ region, a time delay occurs due to slow recombination rate of $\mathrm{O}^{+}$, which is the dominant chemical species in the $\mathrm{F} 2$ region.

Reference [7] showed that, during an eclipse event, the electron density profile experiences a trough in the eclipse zone. The trough is generated by an increase in the charge order processes expressed as

$$
\begin{gathered}
\mathrm{O}^{+}+\mathrm{N}_{2} \longrightarrow \mathrm{NO}^{+}+\mathrm{N} \\
\mathrm{O}^{+}+\mathrm{O}_{2} \longrightarrow \mathrm{O}_{2}^{+}+\mathrm{O}
\end{gathered}
$$

The two charge processes in which $\mathrm{O}^{+}$ions, in the $\mathrm{F} 2$ region, are driven through neutral atmosphere produce $\mathrm{NO}^{+}$and $\mathrm{O}_{2}{ }^{+}$as the dominant species in the $\mathrm{F} 1$ region. Thus, the above processes are known to cause a faster recovery of foF1 (critical frequency of F1 layer) and delayed recovery of foF2 (critical frequency of F2 layer) after the end of the eclipse. Furthermore, during an eclipse event, the stratification of the F layer into F1 and F2 sublayers becomes distinct. According to [8], this is due to a large upward drift of the F layer to higher altitudes during the solar eclipse. This drift may also slow down the diffusion and hence reduce the ionization of the $\mathrm{F} 2$ region and increase the accumulation of ionization in the F1 region, making the stratification more prominent. Besides, the $G$ factor is given by

$$
G=\frac{B^{2}}{a q},
$$

where $B$ is the linear loss coefficient, $a$ is the recombination coefficient, and $q$ is the rate of production of ions and electrons. The $G$ factor quantifies the stratification of the F1 and F2 regions [9]. During solar eclipse, $q$ decreases as the solar disc is obscured and $a$ also decreases as the temperature decreases due to the eclipse shadow region. Hence, the value of $G$ becomes larger around the solar eclipse time, which is attributed to increased stratification of the F layer [10].

There is rich literature on the ionospheric variability due to total solar eclipse events. For example, [11] used GPS receivers located at Wuchang and Guangzhou in China to determine the effect of October 24, 1995, solar eclipse on the ionospheric TEC. The study observed a negative deviation in TEC during the eclipse, which is proportional to the degree of obscuration by the lunar disc. Furthermore, the observed maximum negative deviation from the reference levels recorded during the pre- and posteclipse days ranged from $20 \%$ to $50 \%$. The absolute maximum negative deviation was found to be $1.0 \times 10^{17}$ electrons per square metre at Wuchang, while it was twice at Guangzhou. The maximum deviation was more at Guangzhou due to the fact that it was closer to the center of totality than Wuchang. Therefore, a total eclipse negatively affects the TEC in the ionosphere. In another study, [12] studied the ionospheric response to the total solar eclipse of July 22, 2009, by analyzing the data from four low-latitude GPS stations in India. The ionospheric vertical TEC (VTEC) showed a significant reduction at all the four stations. The authors further showed that the amount of reduction in VTEC decreased as the obscuration decreased. This is a clear manifestation of the direct dependence of electron production on photoionization process. The solar eclipse of July 22, 2009, was again studied by [13]. The authors investigated the behaviour of the ionosphere by measuring the variation in TEC for three (pre-, post-, and eclipse) consecutive days. This eclipse event was complicated by the simultaneous occurrence of a geomagnetic storm which lasted for 10 hours. The results of the GPS data collected from Chongqing and Wuhan and IGS stations at Wuhan and Shao indicated that the instantaneous TEC values declined by about 1-4 TECU at the measurement points depending on the location and time during which the measurement was taken.

Furthermore, [5] studied the effect of the solar eclipse of January 15, 2010, and observed that the decrease in the electron density during the eclipse event occurred throughout the E and F1 layers simultaneously. In the F2 layer, the decrease in electron density began at the lower end and extended progressively towards the peak of the F2 region. The experimental measurements and theoretical simulation of results indicate that the eclipse events have more pronounced effects during the midday than in the morning and afternoon hours [5]. They attributed these effects to the fact that a decrease in solar radiation due to the eclipse event resulted in a decrease in the electron production rate and, consequently, the electron concentration. However, the change in the electron concentration in the F2 layer was affected by photochemical processes as well as electrodynamical and neutral forcing processes.

Reference [2] described observations of the sporadic E (Es) behaviour during the total solar eclipse of July 22, 2009. Es is a thin layer with dense patches of ionization around the $\mathrm{E}$ region. It is generally observed between the altitudes of $95 \mathrm{~km}$ and $120 \mathrm{~km}$. This study observed the variations in Es using high frequency ground-based radio systems and found that the critical frequency of the Es (foEs) obtained using ionosonde observations at Wuhan was enhanced. Again, they found that the hop number and the wave power as recorded by oblique incidence rays from Wuhan to Suzhou (both in China) were increased. Furthermore, the wave Doppler frequency shift (DFS) value of Es was increased. Finally, they observed that the cooling effect of the moon's shadow was believed to induce a powerful meridional air flow in the atmosphere. This was thought to accelerate the ionized clouds in the Es layer and formed the wind shear which raised the observed DFS and foEs values, respectively. During an eclipse event, foEs increases because of the decrease in solar radiation and does not result in a reduction in the electron concentration in Es; instead, the electron concentration increases. This is due to the fact that the meridional air flow accelerates the ionized clouds in Es layer to form the wind shear. It is 


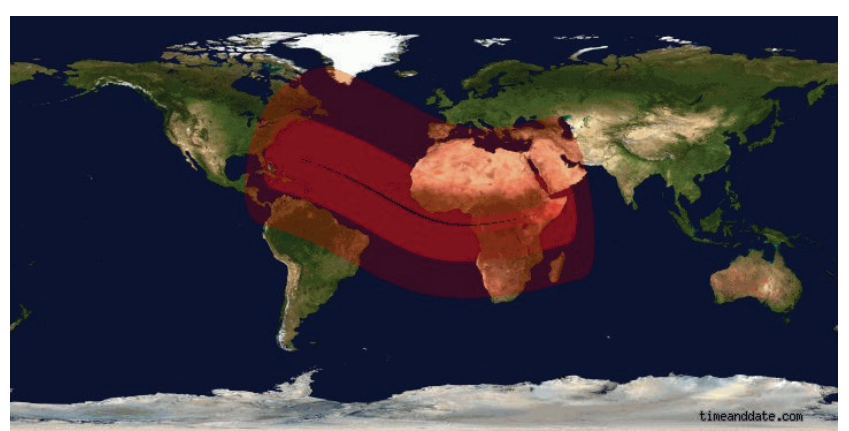

FIGURE 1: Map showing the path of the solar eclipse event of November 03, 2013 (Courtesy of NASA).

this wind shear that induces the intensification in the Es layer $[3,4,14]$ and increases the foEs during solar eclipse events [2]. In this current study, the ionospheric response to the solar eclipse of November 3, 2013, was investigated using TEC data as measured at four GPS receiver stations in Uganda (MBAR), Kenya (MAL2 and MOIU), and Rwanda (NURK). The next subsection briefly describes this particular solar eclipse event.

The solar eclipse of November 3, 2013, was widely referred to as a hybrid solar eclipse due to the occurrence of both annular and total solar eclipse phenomena. The path of lunar umbral shadow moved from the northern Atlantic Ocean through Gabon, Republic of Congo, Democratic Republic of Congo, Uganda, northwestern Kenya, and Ethiopia and ended in Somalia as shown in Figure 1.

The totality of this eclipse lasted for a maximum period of about 1 minute and 39 seconds. In Uganda, the lunar disc was observed to touch the solar disc at around 13:06 UT (16:06 LT), culminating into a total eclipse at 14:22 UT (17:22 LT). The total eclipse had a magnitude of 1.03 . The duration of the total solar eclipse at Owiny $\left(2.56^{\circ} \mathrm{N}, 31.42^{\circ} \mathrm{E}\right)$ was $22.3 \mathrm{sec}-$ onds.

\section{Data Sources and Processing}

The data used in this study was archived at four GPS receiver stations shown in Figure 2. The geophysical parameters of these stations are shown in Table 1.

The GPS_TEC algorithm developed by [15] was used to derive TEC values at the equatorial stations with an elevation mask of $20^{\circ}$. The GPS_TEC algorithm uses the phase and code values associated with the L1 and L2 GPS frequencies to remove the tropospheric water vapour and clock error effects to calculate relative slant TEC. Absolute TEC values are obtained by taking into account the differential satellite biases and the receiver biases [16]. The equivalent VTEC at altitude of $350 \mathrm{~km}$ was calculated by using the thin shell model and averaging the TEC for individual visible satellites. The VTEC derived from the STEC was used to derive the disturbance (VTEC perturbation) in the ionospheric electron density. The data for each GPS station for 2-3 days before and after the eclipse was used as background (quiet day) data to calculate the background mean VTEC ( $\overline{\text { VTEC }})$ of the data points for every 30 seconds. The mean VTEC was then

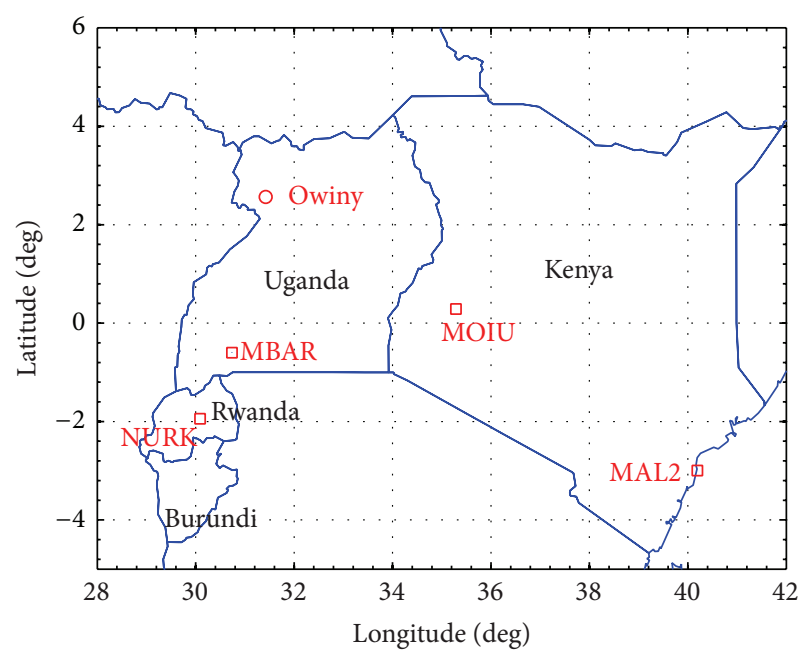

FIGURE 2: Map showing the GPS receiver stations from which data was obtained.

TABLE 1: Geophysical parameters of the dual frequency GPS receiver stations.

\begin{tabular}{lccccc}
\hline \multirow{2}{*}{ Station } & \multirow{2}{*}{ Code } & \multicolumn{2}{c}{ Geogra. coordinates } & \multicolumn{2}{c}{ Geomag. coordinates } \\
& & Long. $\left({ }^{\circ} \mathrm{E}\right)$ & Lat. $\left({ }^{\circ} \mathrm{S}\right)$ & Long. $\left({ }^{\circ} \mathrm{E}\right)$ & Lat. $\left({ }^{\circ} \mathrm{S}\right)$ \\
\hline Malindi & MAL2 & 40.19 & 2.30 & 111.63 & 6.73 \\
Eldoret & MOIU & 35.29 & -0.29 & 107.64 & 2.69 \\
Mbarara & MBAR & 30.74 & 0.60 & 102.99 & 2.82 \\
Kigali & NURK & 30.09 & 1.94 & 102.13 & 4.03 \\
\hline
\end{tabular}

subtracted from the disturbed day VTEC to obtain the perturbation $(\triangle \mathrm{VTEC})$, similar to [12]:

$$
\triangle \mathrm{TEC}=\mathrm{VTEC}-\overline{\mathrm{VTEC}} .
$$

Wavelet analysis was done using the TEC perturbation data and the results are shown in Figure 6. Wavelet analysis provides information on the temporal characteristics of the signal. Spectral analysis performed in this study implemented wavelet transform presented in [17]. The Morlet wavelet was chosen as the mother wavelet because it consists of a plane wave modulated by a Gaussian.

\section{Results}

This section presents results based on TEC measurements from four equatorial GPS stations. The results entail variability of VTEC, VTEC perturbation ( $\triangle \mathrm{TEC}$ ), and TEC along signal path (STEC). The results also include wavelet analysis for determining the presence of wave-like structures and traveling ionospheric disturbances (TIDs). The period from 01 to 04 November 2013 was geomagnetically quiet; thus, no results based on geomagnetic data have been presented. The derived VTEC showed a significant reduction with a maximum of $\leq 35$ TECU in Figure 3(b) between 17:00 and 19:00 UT. The reduction in VTEC depends on latitude as well as longitude, 


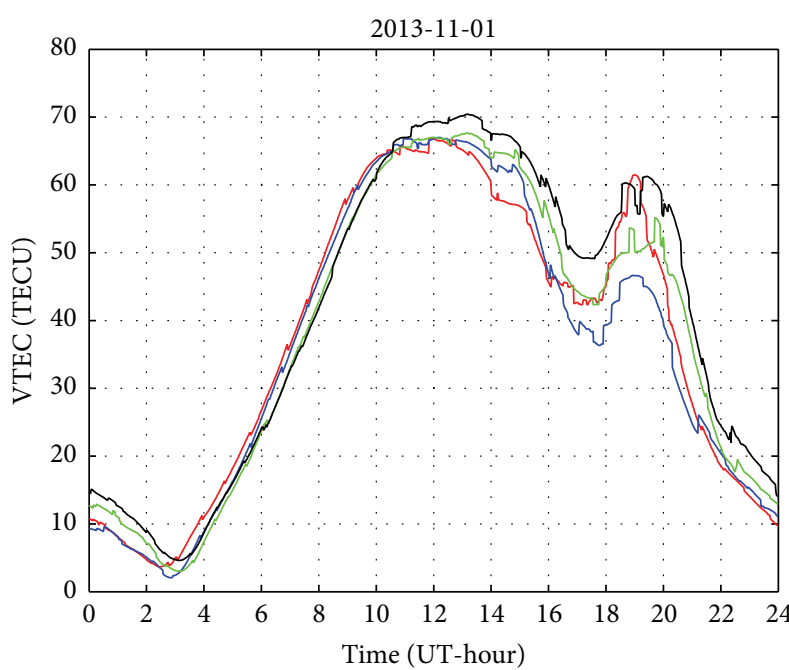

(a)

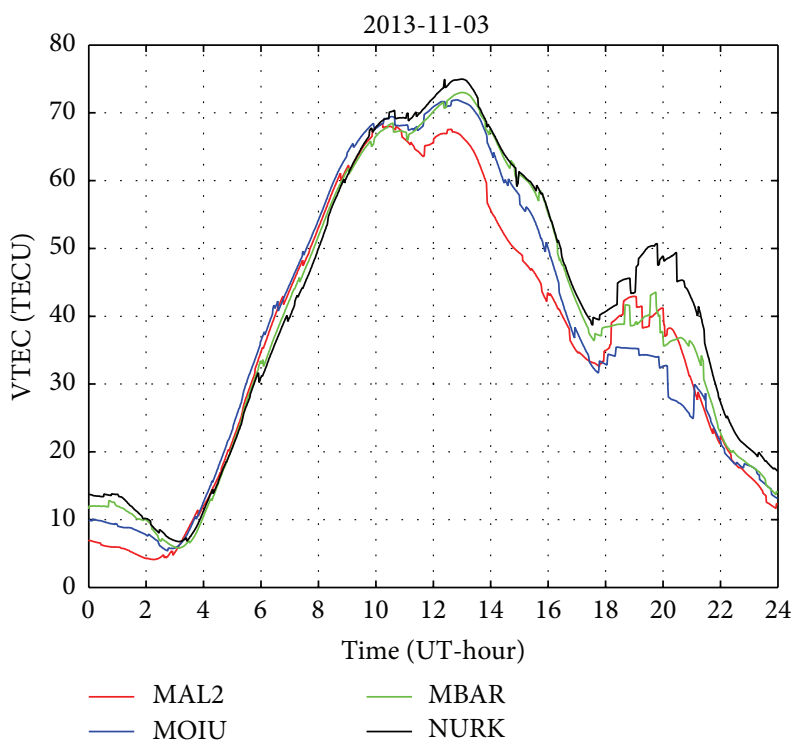

(c)

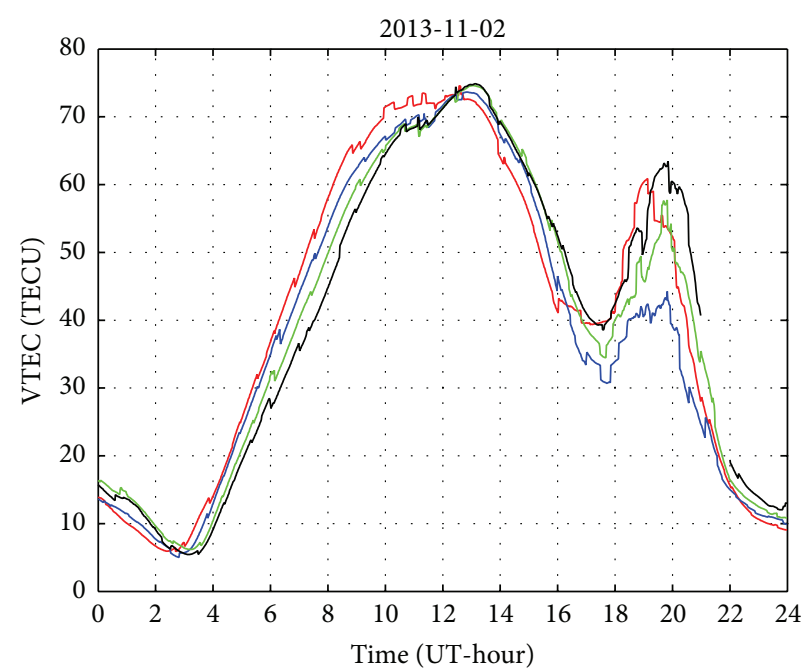

(b)

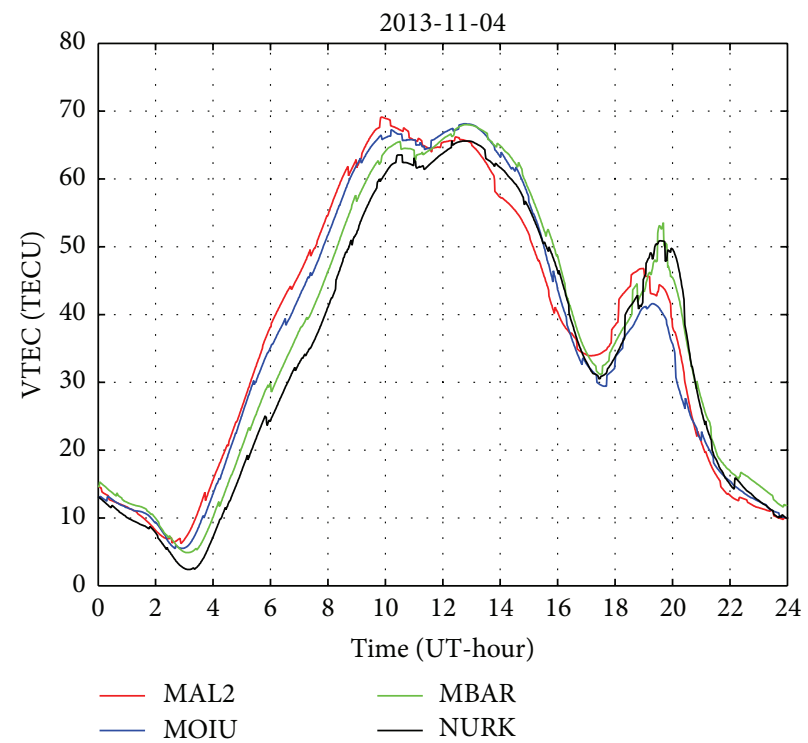

(d)

FIGURE 3: Variation of VTEC recorded at four equatorial GPS stations from 01 to 04 November 2013. East African standard time, LT = UT + 3 hours.

which also depends on the location of the satellite with respect to the solar eclipse path [12]. The amount of reduction in VTEC is proportional to the obscuration of the lunar disc, which is directly related to the electron production by the photoionization process [12]. Figures 3(a), 3(b), 3(c), and 3(d) show that the VTEC decreases gradually from around 14:00 UT to minimum values at 17:17 UT, 17:37 UT, 17:37 UT, and 17:24 UT, respectively. The maximum VTEC values are at $\sim 70$ TECU in Figures 3(a) and 3(d) and 75 TECU in Figures 3(b) and 3(c). Thus, the decrease in VTEC closely follows the evolutionary pattern of the eclipse. As the obscuration decreased, VTEC started recovering (after 18:00 UT), possibly due to photoionization by partial solar radiation falling into the atmosphere [12]. After 18:00 UT (21:00 LT), solar eclipse ceases and normal photoionization resumed.
Several studies of TEC variability $[18,19]$ have shown higher daytime TEC values during the equinoctial months, moderate values during the summer, and the least values in the winter months. This particular eclipse of November 03 , 2013, lies within winter season. During sunrise, the magnetic flux tubes get filled up because of their small volume resulting in sudden increase in ionization due to increasing thermospheric temperatures $[18,19]$. The gradual increase in TEC to a maximum value at peak hours of the day at these equatorial latitude stations could be attributed to the solar extreme ultraviolet (EUV) ionization coupled with the upward vertical $\mathbf{E} \times \mathbf{B}$ drift. The observed nighttime TEC enhancements may be attributed to tidal winds which blow the ionization across geomagnetic fields. Meanwhile, the nighttime decrease could be due to the small size of the magnetic flux 


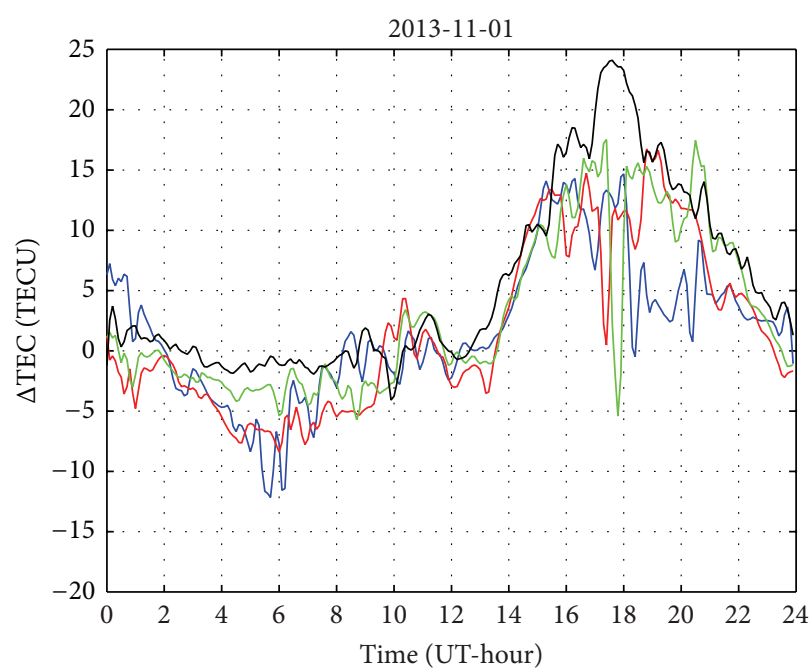

(a)

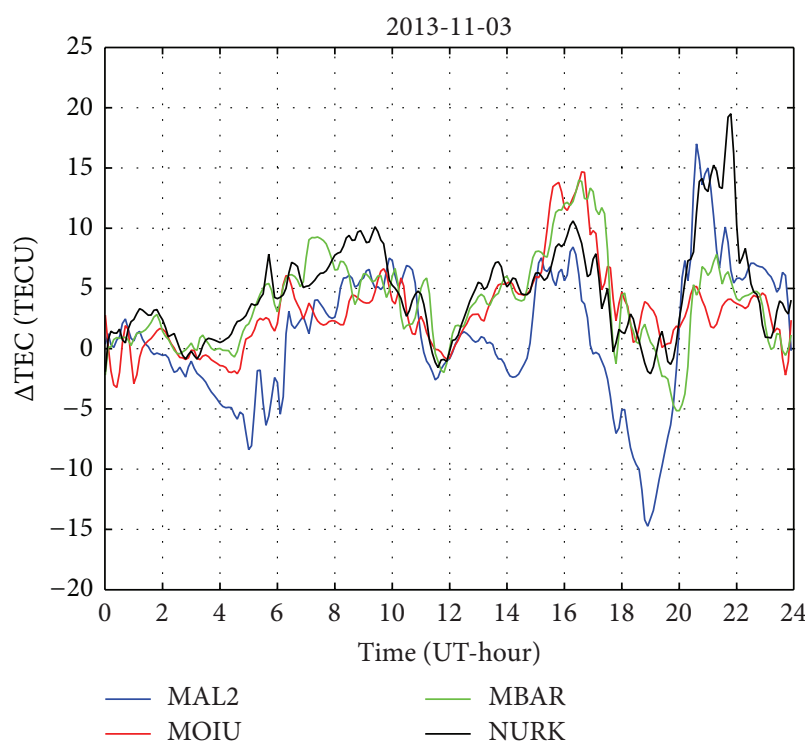

(c)

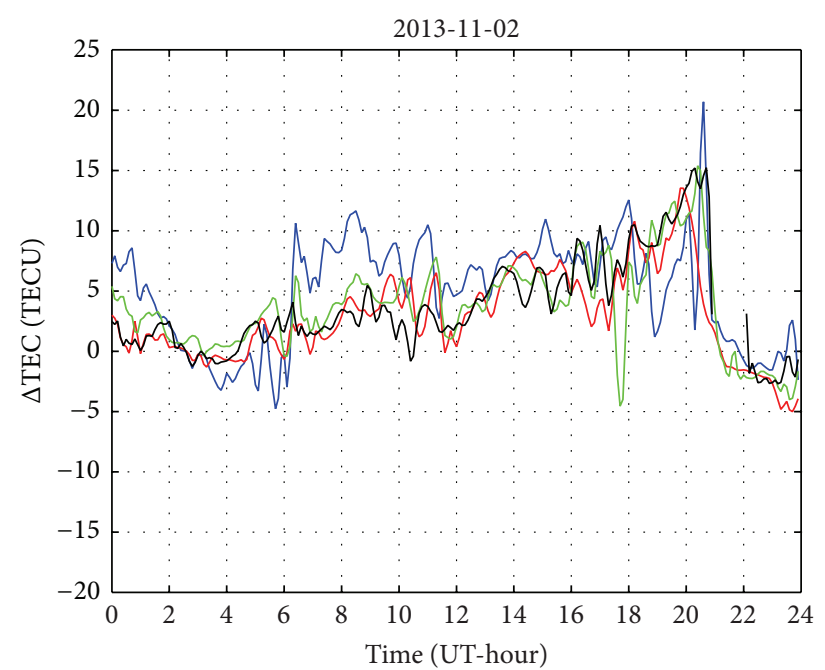

(b)

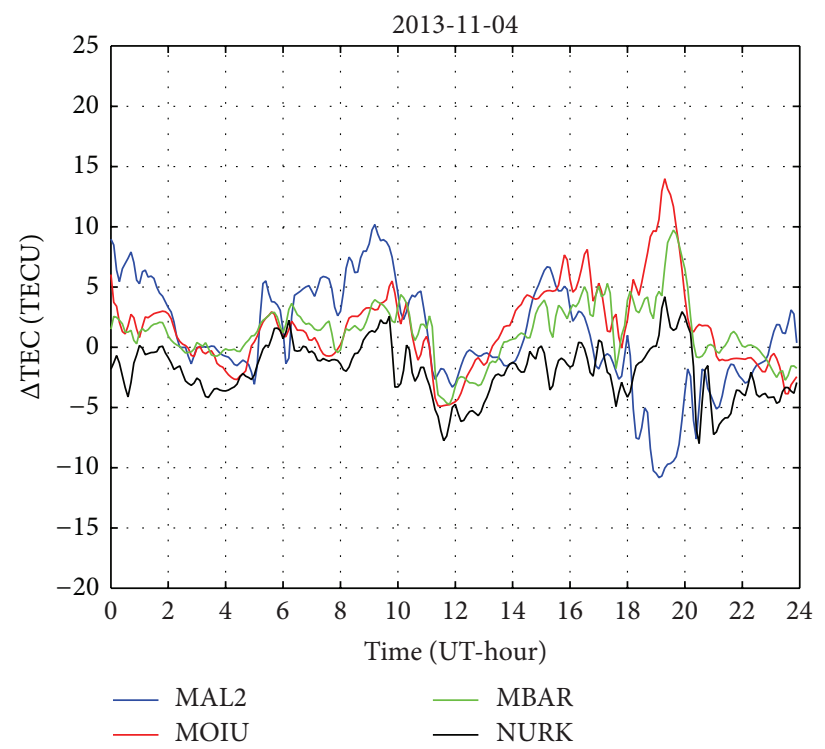

(d)

FIGURE 4: Variability of VTEC perturbation for two days before eclipse event ((a) and (b)), during eclipse event (c), and one day after the eclipse event (d).

tubes that makes the electron content in these tubes collapse rapidly after sunset in response to the low temperatures in the thermosphere at night, leading to low TEC values $[18,19]$.

Generally, the results showed that TEC enhancement was observed from 13:00 to 17:45 UT (refer to Figure 4(a)), and later a gradual decrease in TEC. The peak of the TEC enhancement was observed at 17:43 UT (NURK), during which opposite polarity of VTEC perturbation was observed at MAL2, MOIU, and MBAR. The perturbation levels were low ( $\leq 10$ TECU) in Figure 4(b), except between 17:30 and 21:30 UT. The TEC depletions observed after the eclipse event in Figure 4(d) were higher than those before (Figure 4(b)) the eclipse event. The study observed a negative deviation in TEC ( $\geq 20$ TECU) during the eclipse proportional to the degree of obscuration by the lunar disc as shown in Figure 4(c).
Furthermore, the observed maximum negative deviation recorded during the pre- and posteclipse days ranges from 5 to 15 TECU. Measurements from the four stations showed reduction in the amount of incoming solar radiation after the eclipse onset. The size of the reduction is closely related to the eclipse magnitude [20]. Changes induced in the spectral solar irradiance during the eclipse resulted in decreased photoionization activity in the ionosphere. The ionospheric response to solar eclipse varies with latitude variations. Figure 4(c) shows that maximum perturbation amplitude of $\geq 20$ TECU (18:00-20:00 UT) was observed at MAL2 which is further south of the equator than the other stations. The same figure shows that TEC enhancement and depletion occurred during the totality of the eclipse at MOIU, MBAR, NURK, and MAL2 (13:00 to 15:00 UT). The different behavior of F2 

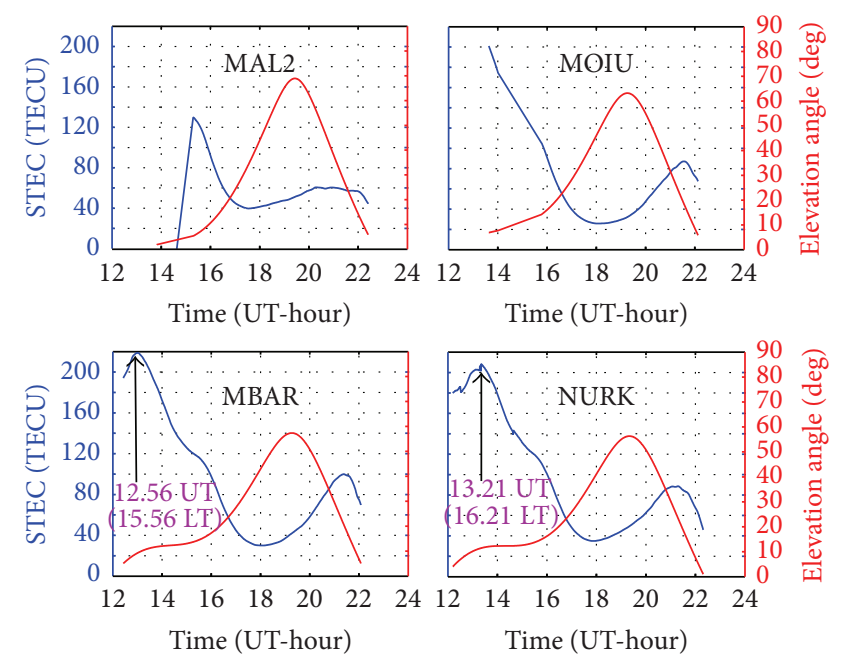

(a)
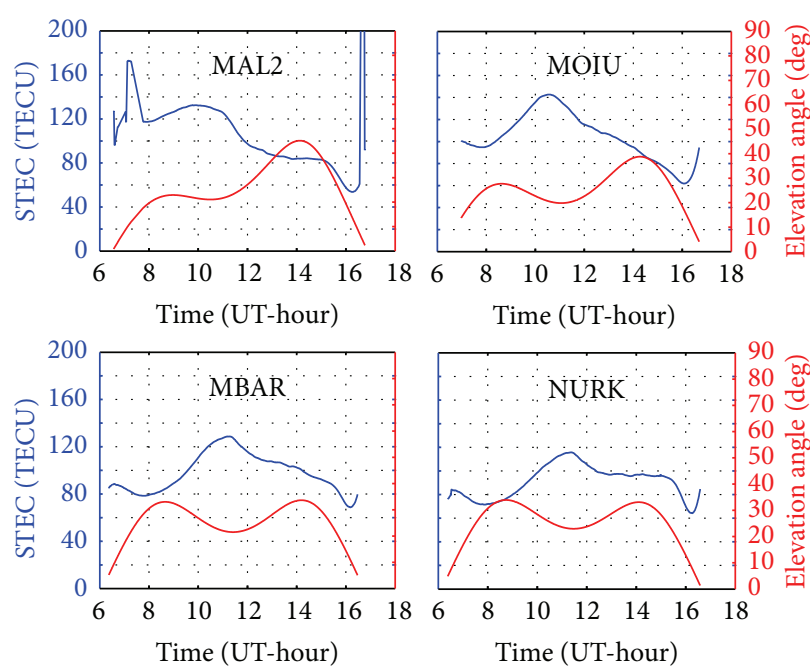

(c)
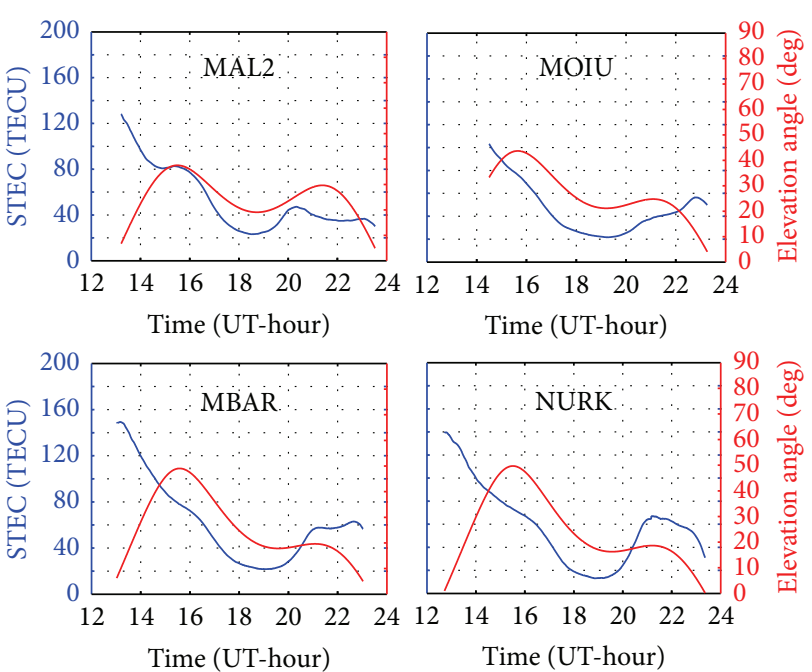

(b)
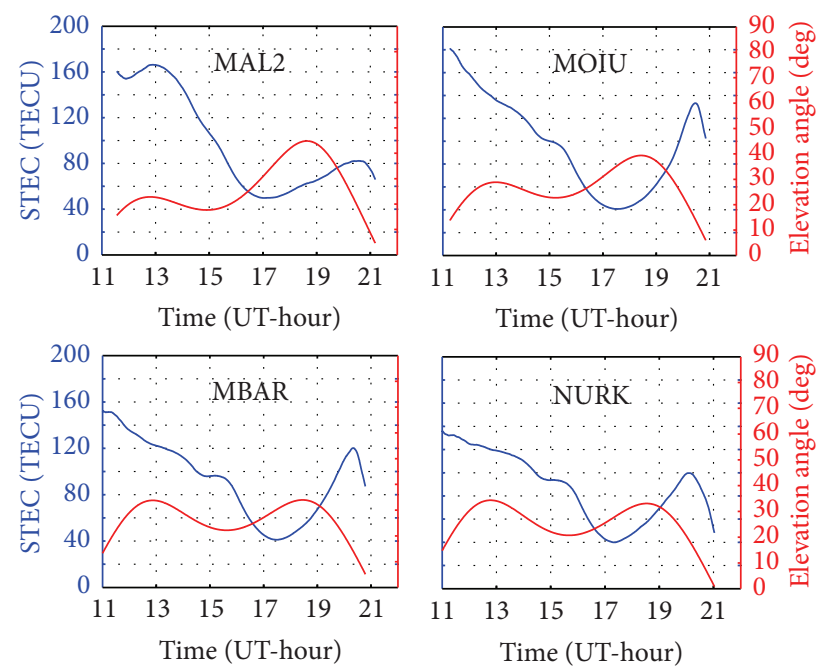

(d)

Figure 5: TEC observed along the ray paths between the receiver stations and PRN 20 (panel (a)), PRN 23 (panel (b)), PRN 30 (panel (c)), and PRN 32 (panel (d)) on 2013-11-03.

layer may be due to the fact that electron density is more controlled by the transport process than by the production rate [12]. However, TEC decrease during solar eclipse is dependent on latitude and local time [12] (references herein). The latitudinal variation may arise due to the latitudinal variation of magnetic inclination angle, which influences plasma diffusion. The dependence on local time is attributed to the rate of electron loss, which is related to the local-time dependent background density [12]. However, processes such as equatorial electrojet (EEJ) and the equatorial ionospheric anomaly (EIA) may complicate detection of the impact of solar eclipse in the equatorial region. The oscillatory nature of VTEC perturbation at all stations may be attributed to gravity wave effects generated in the lower atmosphere during the total solar eclipse [12].

The TEC observed along the ray path between pseudorandom number (PRN) 20 and the GPS receivers at MOIU,
MBAR, and NURK shows significant depletions between 17:00 and 20:00 UT (Figure 5(a)). A similar TEC pattern (but of lower magnitude) was observed along the ray path between PRN 23 and the receivers at MAL2, MBAR, and NURK between 16:00 and 20:00 UT (Figure 5(b)). TEC enhancements of low amplitude were observed along the ray paths satellite 30 and the four receiver stations between 08:00 and 14:00 UT (Figure 5(c)). The TEC along the ray path between PRN 32 and the four receiver stations revealed depletions between 15:00 and 20:00 UT (Figure 5(d)). These depletions were observed when the satellite was at least above $20^{\circ}$ elevation. The amplitude of the TEC depletions is at least 40 TECU for all the four satellites as observed from the four stations. The start of the eclipse was observed by PRN 20 as seen from MBAR (12:56 UT) and NURK (13:21 UT) as shown in Figure 5(a). The eclipse was observed at the low latitude station (MBAR) before that of the slightly higher latitude 


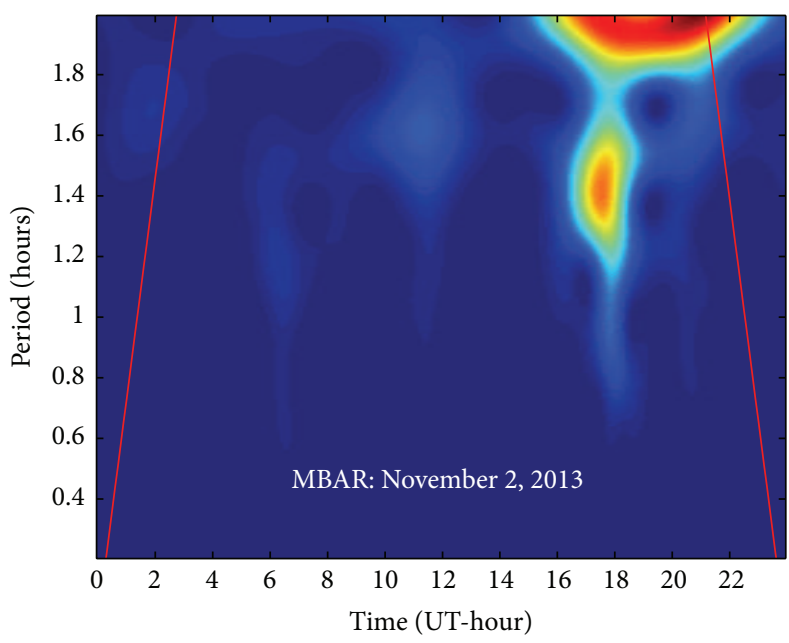

(a)

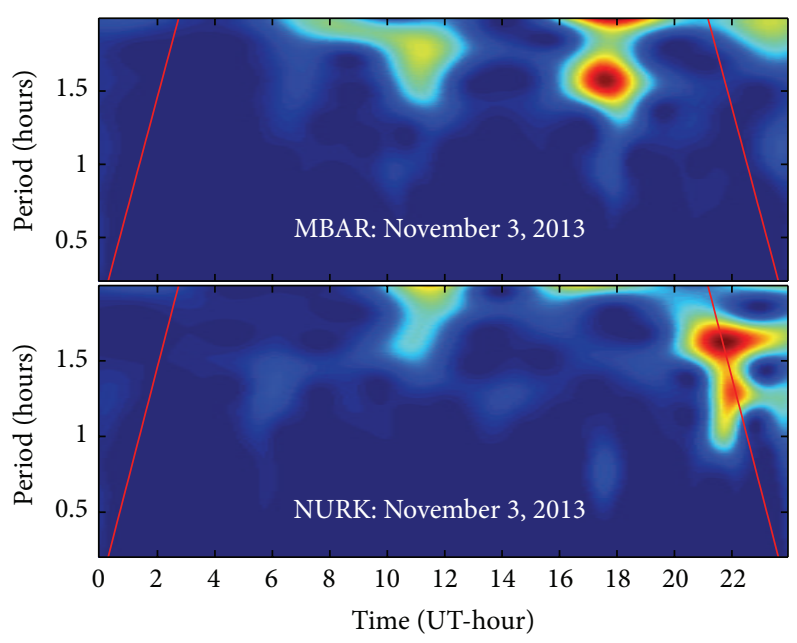

(c)

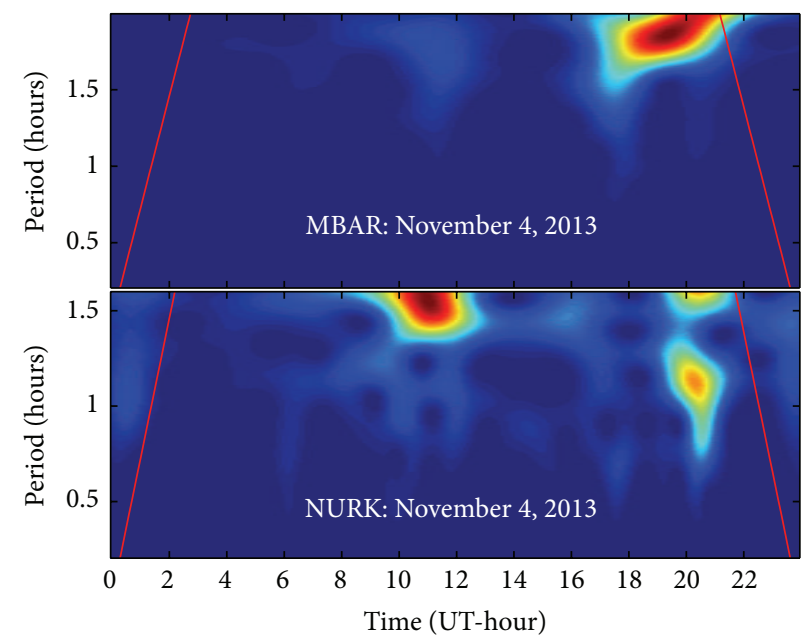

(e)

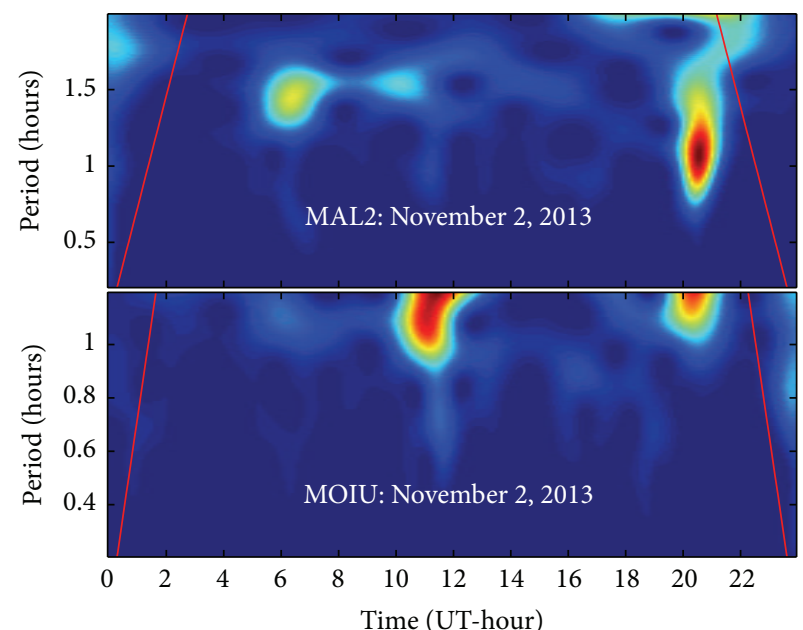

(b)

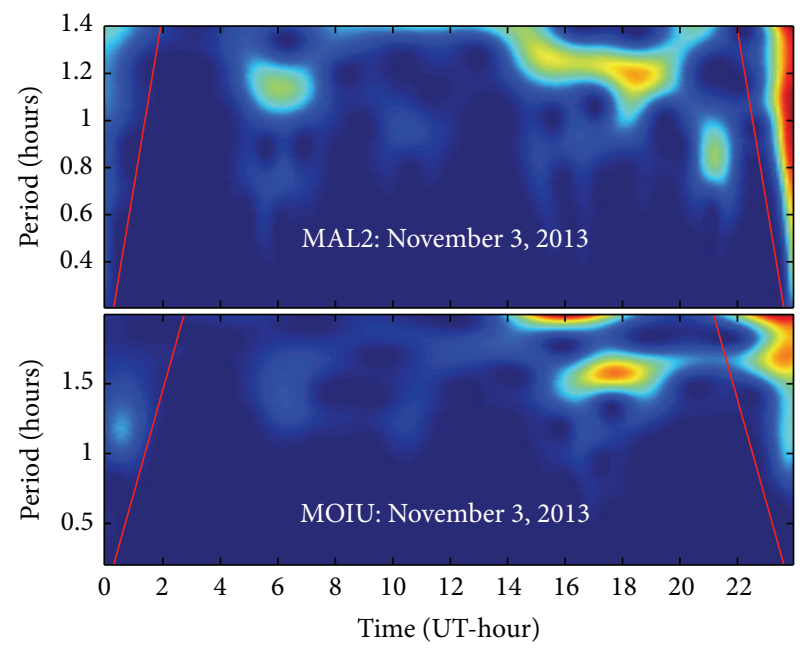

(d)

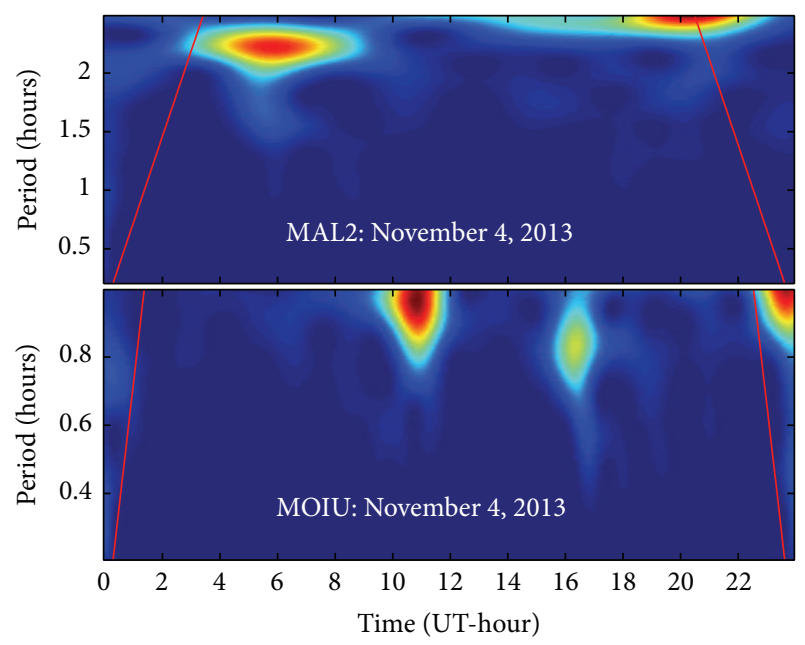

(f)

FIGURE 6: Wavelet transforms of diurnal TEC for one day before ((a) and (b)), after ((e) and (f)), and during ((c) and (d)) the eclipse event. 

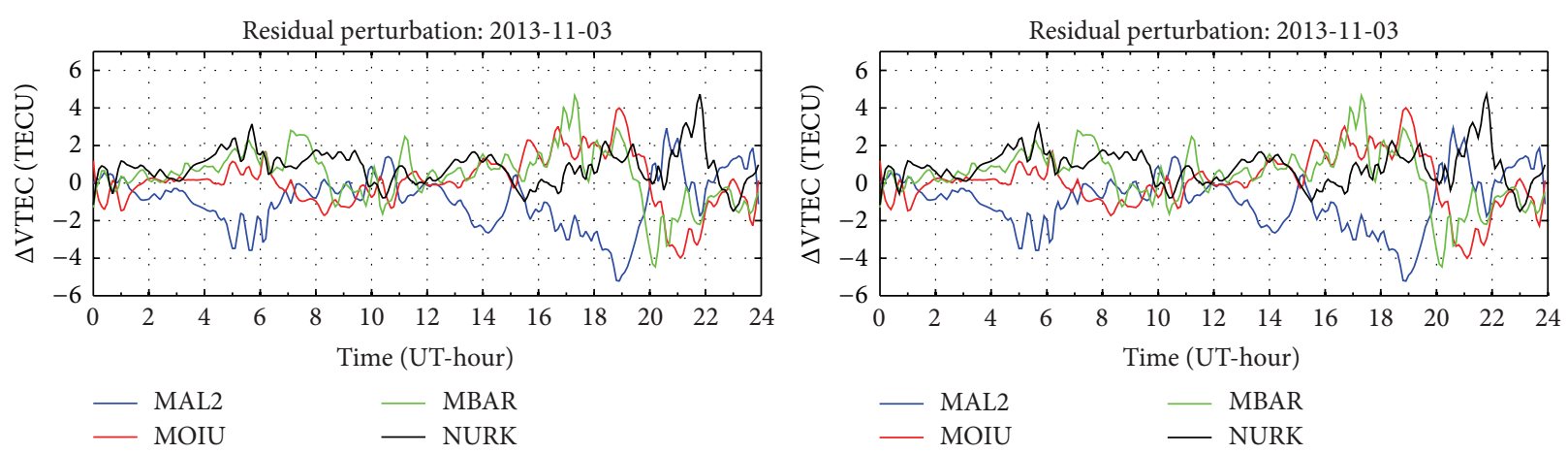

(a)
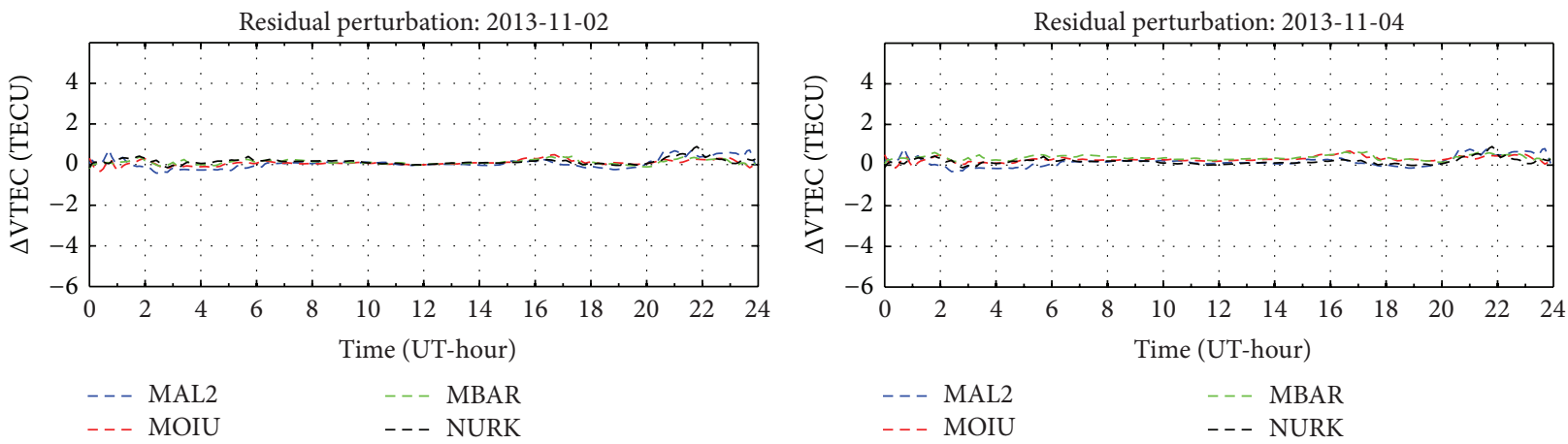

(b)
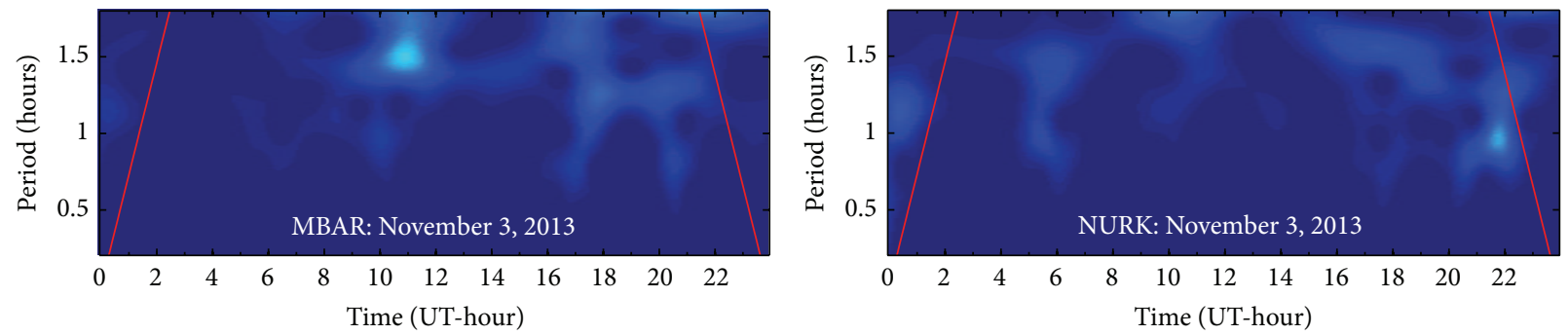

(d)

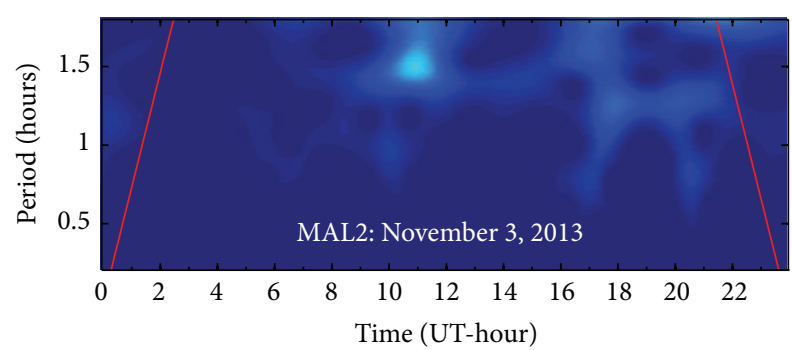

(f)

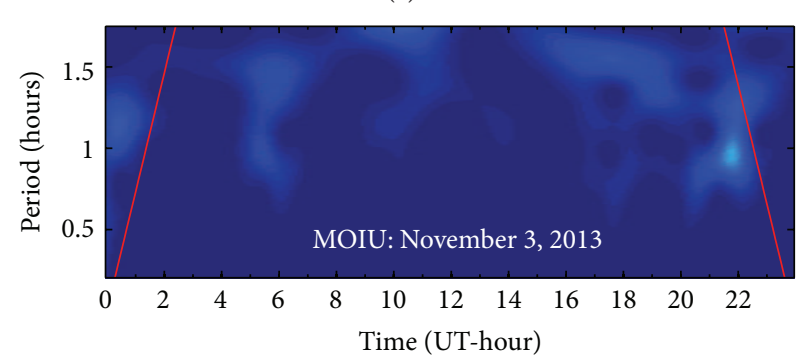

(g)

FIGURE 7: Residual diurnal TEC perturbations for one day before (a) and after (b) the eclipse event compared with that of November 03, 2013. Wavelet transforms of the residual TEC perturbations during the total eclipse event ((d), (e), (f), and (g)).

station (NURK). The effect of the eclipse therefore seems to show latitudinal dependence. This could be attributed to the $\mathbf{E} \times \mathbf{B}$ vertical plasma drift that may influence the equatorial ionosphere during a solar eclipse. Most likely, the large plasma depletions at the low latitudes get transported to high latitudes through the plasma vertical drift [12] (references herein).
Spectral analysis of the diurnal TEC shows the presence of gravity waves of slightly different periods before, during, and after the eclipse event. The red line shows the cone of influence, which describes the region within which information can be considered significant. Wave-like structures of periods ranging from 1.0 to 1.5 hours were observed at MBAR (06-12 UT and 16-19 UT), MAL2 (06-08 UT and 14-20 UT), 
MOIU (16-20 UT), and MOIU (10-12 UT), on the day of eclipse. Similar wave-like structures with periods between 1.0 hour and 2.5 hours were also observed at the four stations a day after the eclipse event. A day before the eclipse, high intensity gravity waves having periods of 1-2 hours were observed at MBAR (16-22 UT), MAL2 (20-22 UT), and MOIU (10-12 UT). According to [21], these waves have periods corresponding to large scale TIDs (LSTIDs). TIDs are known to be generated due to the interaction between thermospheric gravity waves and the ionosphere.

The TEC perturbations in Figure 4(c) consist of contributions from wave-like structures (or TIDs) and obscuration of the solar radiation during the total eclipse event. To isolate contributions to the TEC perturbation due to the solar eclipse, TEC perturbations for November 01, 02, and 04, 2013, were averaged and then subtracted from that of November 03 , 2013. The results are shown in Figure 7.

Figures $7(\mathrm{~b})$ and 7 (c) show that the daily residual TEC perturbations for November 01, 02, and 04, 2013, are approximately zero. Meanwhile, significant residual TEC perturbations were observed on the day of eclipse (November 03, 2013) as shown in Figure 7(a). TEC depletions of $\sim 3$ TECU (4-6 UT) and 5 TECU (16-19 UT) were observed at MAL2, after which TEC started recovering. The other three stations mostly revealed small TEC enhancements of varying amplitude. To further confirm the presence of wave-like structures (TIDs) that can modulate TEC, wavelet analysis was applied on the residual TEC perturbations. The results in Figures $7(\mathrm{~d}), 7(\mathrm{e}), 7(\mathrm{f})$, and $7(\mathrm{~g})$ confirm that TID contributions to the TEC perturbations in Figure 4(c) have been minimized. It can be assumed here that the TEC perturbations in Figure 7(a) are entirely due to obscuration of solar UV radiation, which led to varying ionization levels in the ionosphere. Hence, ionospheric TEC on November 03, 2013, was modified by the passage of wave-like structures and the obscuration of the solar disc during the solar eclipse event.

\section{Conclusion}

The study investigated the response of the equatorial ionosphere towards the solar eclipse of November 03, 2013. GPS L-band TEC data over the East African region was used for tracking the effect of the eclipse on the ionospheric electron density concentration. The results show that TEC enhancement and depletion were observed during the time of totality of the eclipse at MOIU, MBAR, NURK, and MAL2 (13:00 to 15:00 UT). Maximum TEC perturbation amplitude of $\geq 20$ TECU (18:00-20:00 UT) was observed at MAL2, further south of the equator than the other three stations. TEC depletions ( $\geq 40$ TECU) were observed along the ray path between PRN 20 (17:00-20:00 UT) and the GPS receivers at MOIU, MBAR, and NURK. TEC enhancements of low amplitude were observed along the ray paths between PRN 30 and the four receiver stations between 08:00 and 14:00 UT. The eclipse started at 12:56 UT and 13:21 UT as observed by PRN 20 from MBAR and NURK, respectively. Generally, the ionospheric TEC on November 03, 2013, was observed to be modified by wave-like energy and momentum transfer and obscuration of the solar disc during the total eclipse.

\section{Conflict of Interests}

The authors declare that there is no conflict of interests regarding the publication of this paper.

\section{Acknowledgments}

The authors acknowledge the International Science Program (ISP) for funding this study. The authors acknowledge Astronomers Without Borders, especially Simons Maduit, who effectively coordinated the mobilization of solar viewers for the eclipse event. The authors also acknowledge the reviewer(s) for the concerns raised that have led to the improvement of the quality of the paper. IGS data used in this study was downloaded from ftp://data-out.unavco.org/pub/ rinex/obs.

\section{References}

[1] E. Gerasopoulos, C. S. Zerefos, I. Tsagouri et al., "The total solar eclipse of March 2006: overview," Atmospheric Chemistry and Physics, vol. 8, no. 17, pp. 5205-5220, 2008.

[2] G. Chen, Z. Zhao, C. Zhou, G. Yang, and Y. Zhang, "Solar eclipse effects of 22 July 2009 on sporadic-E”, Annales Geophysicae, vol. 28, no. 2, pp. 353-357, 2010.

[3] J. D. Mathews, "Sporadic E: current views and recent progress," Journal of Atmospheric and Solar-Terrestrial Physics, vol. 60, no. 4, pp. 413-435, 1998.

[4] J. D. Whitehead, "Recent work on mid-latitude and equatorial sporadic-E," Journal of Atmospheric and Terrestrial Physics, vol. 51, no. 5, pp. 401-424, 1989.

[5] C. K. Nayak, D. Tiwari, K. Emperumal, and A. Bhattacharyya, "The equatorial ionospheric response over Tirunelveli to the 15 January 2010 annular solar eclipse: observations," Annales Geophysicae, vol. 30, no. 9, pp. 1371-1377, 2012.

[6] A. A. Mansoori, P. A. Khan, P. Bhawre, P. K. Purohit, and A. K. Gwal, "Solar eclipses and ionospheric effects: some historical perspectives," International Journal of Geomatics and Geophysics, vol. 1, pp. 662-668, 2011.

[7] J. M. Holt, R. H. Wand, and J. V. Evans, "Millstone Hill measurements on 26 February 1979 during the solar eclipse and formation of a midday F-region trough," Journal of Atmospheric and Terrestrial Physics, vol. 46, no. 3, pp. 251-264, 1984.

[8] H. Chun-Ming, "The effect of upward plasma drift on the F2-layer during the solar eclipse," Journal of Atmospheric and Terrestrial Physics, vol. 36, no. 10, pp. 1701-1703, 1974.

[9] H. Rishbeth and O. K. Garriott, Introduction to Ionospheric Physics, Academic Press, New York, NY, USA, 1969.

[10] P. V. S. Rama Rao, D. S. V. V. D. Prasad, P. Sri Ram, and P. T. Jayachandran, "Ionospheric changes observed over Waltair (Dip $20^{\circ} \mathrm{N}$ ) during the total solar eclipse of 24th October 1995," Terrestrial, Atmospheric and Oceanic Sciences, vol. 8, no. 2, pp. 203-212, 1997.

[11] J. S. Xu, S. Y. Ma, and Q. Wu, "Observations of the ionospheric total electron contents during the solar eclipse of October 24, 1995 by using the GPS beacon," Terrestrial, Atmospheric and Oceanic Sciences, vol. 8, no. 2, pp. 179-188, 1997. 
[12] S. Kumar, A. K. Singh, and R. P. Singh, "Ionospheric response to total solar eclipse of 22 July 2009 in different Indian regions," Annales Geophysicae, vol. 31, no. 9, pp. 1549-1558, 2013.

[13] A. Jia-Chun, W. Ze-Min, E. Dong-Chen, and S. Wei, "Ionospheric behaviour during the solar eclipse of 22 July 2009 and its effect on positioning," Chinese Journal of Geophysics, vol. 53, pp. 731-739, 2009.

[14] J. D. Whitehead, "The formation of the sporadic-E layer in the temperate zones," Journal of Atmospheric and Terrestrial Physics, vol. 20, no. 1, pp. 49-58, 1961.

[15] G. K. Seemala and C. E. Valladares, "Statistics of total electron content depletions observed over the South American continent for the year 2008," Radio Science, vol. 46, no. 5, 2011.

[16] E. B. Amabayo, L.-A. McKinnell, and P. J. Cilliers, "Ionospheric response over South Africa to the geomagnetic storm of 11-13 April 2001," Journal of Atmospheric and Solar-Terrestrial Physics, vol. 84-85, pp. 62-74, 2012.

[17] C. Borries, N. Jakowski, and C. Jacobi, "Observation of large scale waves in the thermosphere-ionosphere system," in Proceedings of ESA's Second Swarm International Science Meeting, 2010.

[18] V. Chauhan, O. P. Singh, and B. Singh, "Diurnal and seasonal variation of GPS-TEC during a low solar activity period as observed at a low latitude station Agra," Indian Journal of Radio and Space Physics, vol. 40, no. 1, pp. 26-36, 2011.

[19] S. Oron, F. M. D’ujanga, and T. J. Ssenyonga, "Ionospheric tec variations during the ascending solar activity phase at an equatorial station, Uganda," Indian Journal of Radio and Space Physics, vol. 42, no. 1, pp. 7-17, 2013.

[20] D. Founda, D. Melas, S. Lykoudis et al., "The effect of the total solar eclipse of 29 March 2006 on meteorological variables in Greece," Atmospheric Chemistry and Physics, vol. 7, no. 21, pp. 5543-5553, 2007.

[21] E. B. Amabayo, J. Edward, P. J. Cilliers, and J. B. Habarulema, "Climatology of ionospheric scintillations and TEC trend over the Ugandan region," Advances in Space Research, vol. 53, no. 5, pp. 734-743, 2014. 

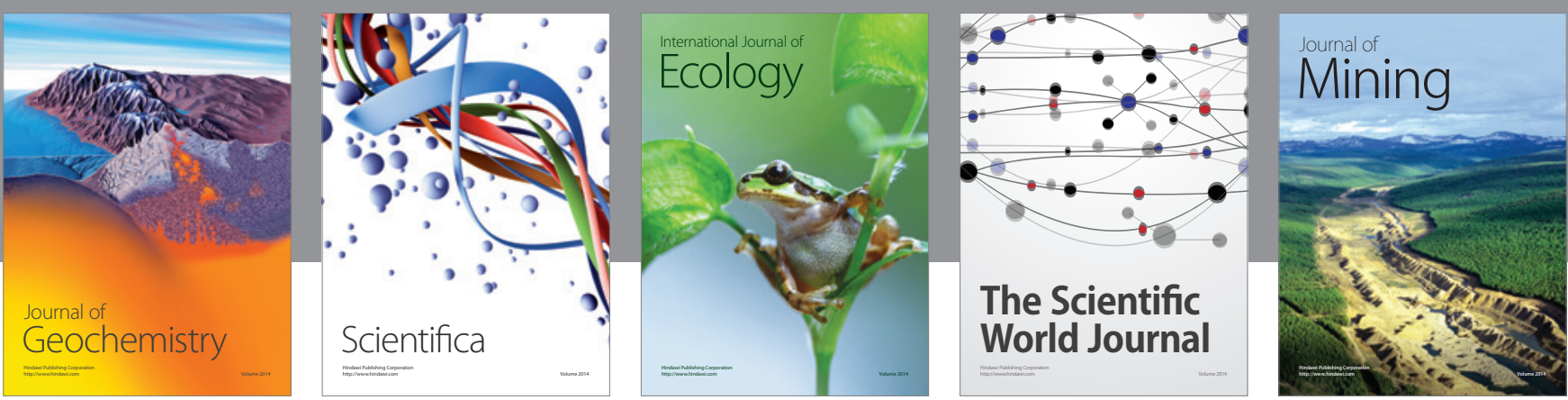

The Scientific World Journal
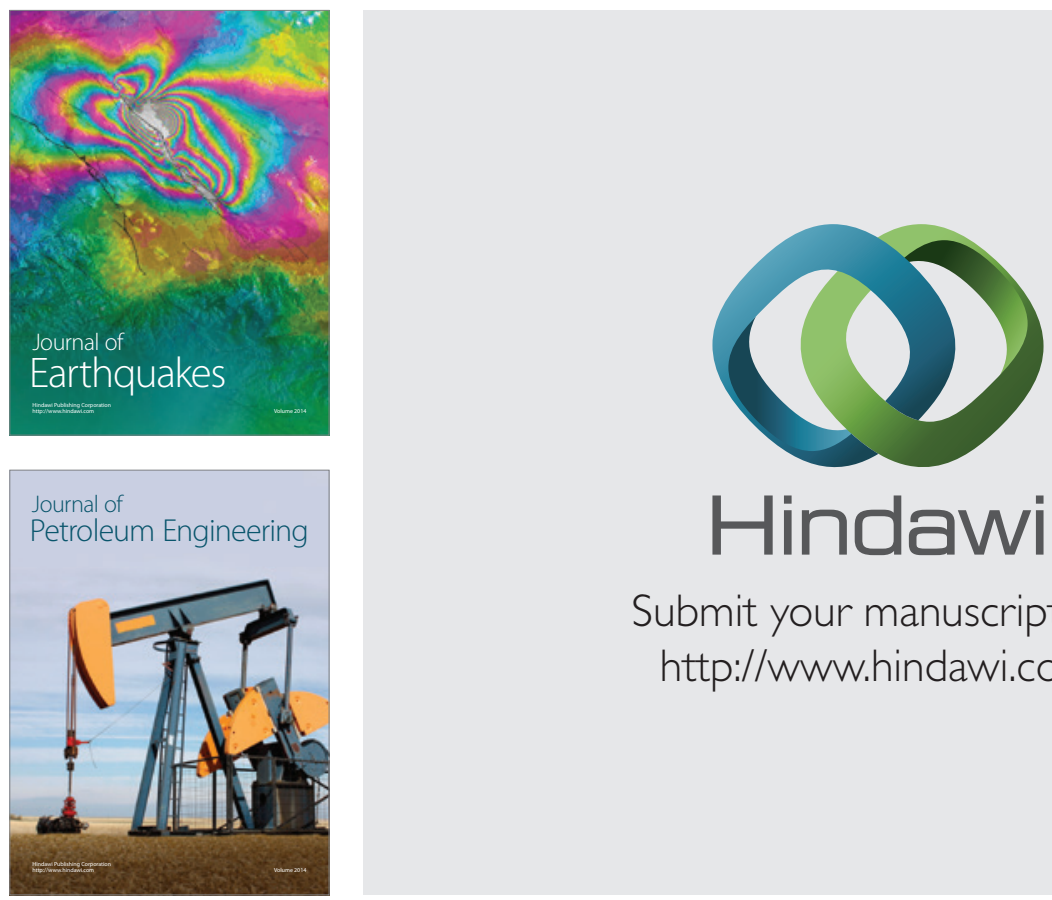

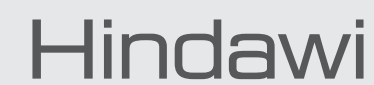

Submit your manuscripts at

http://www.hindawi.com
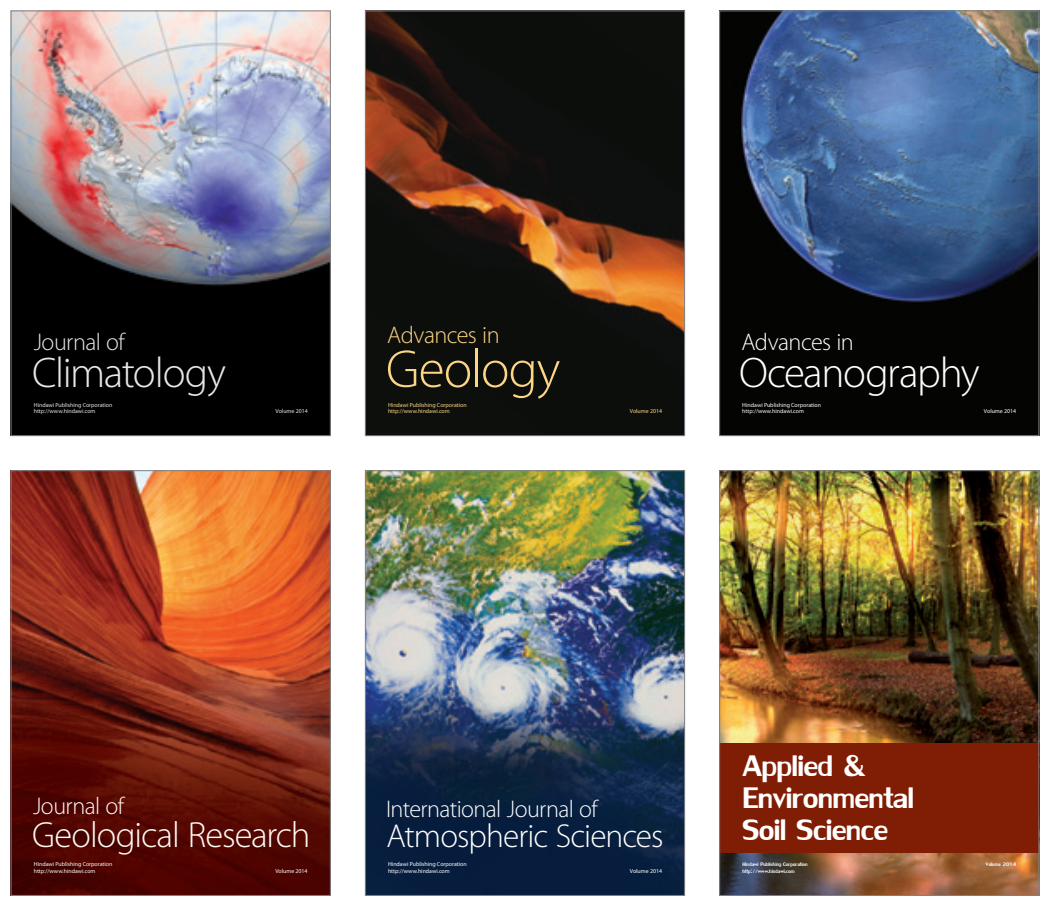
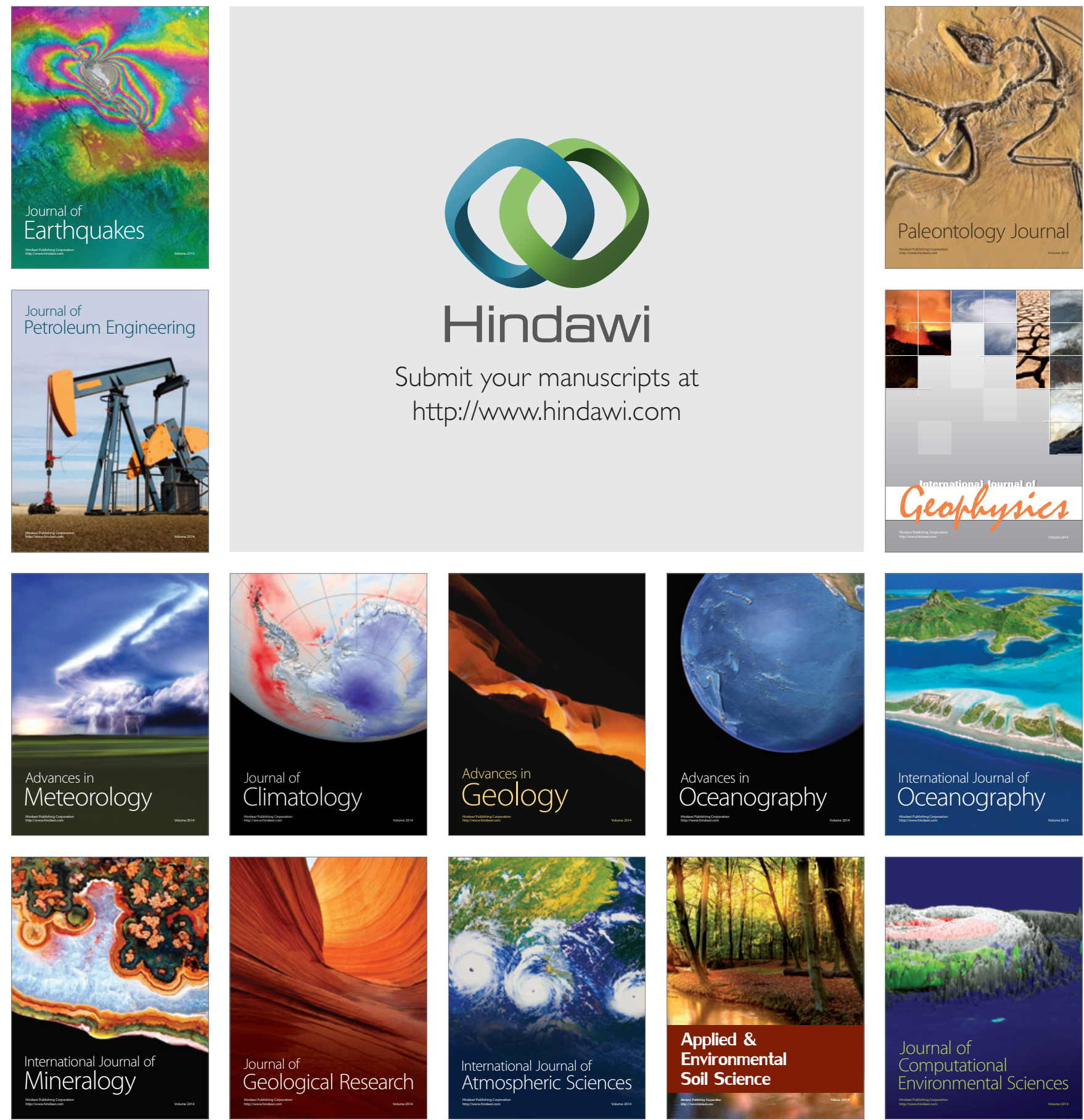